\title{
The CSGU: A Measure of Controllability, Stability, Globality, and Universality Attributions
}

\author{
Pete Coffee and Tim Rees \\ University of Exeter
}

\begin{abstract}
This article reports initial evidence of construct validity for a four-factor measure of attributions assessing the dimensions of controllability, stability, globality, and universality (the CSGU). In Study 1, using confirmatory factor analysis, factors were confirmed across least successful and most successful conditions. In Study 2, following less successful performances, correlations supported hypothesized relationships between subscales of the CSGU and subscales of the CDSII (McAuley, Duncan, \& Russell, 1992). In Study 3, following less successful performances, moderated hierarchical regression analyses demonstrated that individuals have higher subsequent self-efficacy when they perceive causes of performance as controllable, and/or specific, and/or universal. An interaction for controllability and stability demonstrated that if causes are perceived as likely to recur, it is important to perceive that causes are controllable. Researchers are encouraged to use the CSGU to examine main and interactive effects of controllability and generalizability attributions upon outcomes such as self-efficacy, emotions, and performance.
\end{abstract}

Keywords: generalizability, confirmatory factor analysis, self-efficacy, sport psychology

Attributions are explanations about why particular behaviors occurred, and explanations enhance people's ability to predict and control events in the future (Anderson \& Riger, 1991). With reference to the measurement of attributions in sport psychology, Crocker, Eklund, and Graham (2002) emphasized the need for instrument development, and Rees, Ingledew, and Hardy (2005) encouraged researchers to assess an expanded conceptualization of generalizability attributions. In the current article, three studies are presented that provide initial evidence of construct validity for a novel four-factor measure of attributions.

A central premise within attribution research is that there is a dimensional structure underpinning the reasons people give for their successes and failures. In sport psychology, the primary influence on attribution research has been Weiner's

The authors are with the School of Sport and Health Sciences, University of Exeter, Exeter, Devon, U.K. 
attributional theory of achievement motivation and emotion (Weiner, 1979, 1985). According to Weiner, there are three principal attribution dimensions: locus of causality, stability, and controllability. Locus of causality refers to whether the cause is inside (internal) or outside (external) the person. Stability refers to whether the cause will (unstable) or will not (stable) change over time. Controllability refers to whether the cause is controllable or uncontrollable.

The most widely used state attribution measures are the Causal Dimension Scale and the Causal Dimension Scale II. The Causal Dimension Scale (CDS; Russell, 1982) was developed to reflect Weiner's (1979) three-dimensional model of attributions. A number of methodological criticisms have been leveled at the CDS, in particular, concerns over the nature of the controllability subscale (see, e.g., Biddle \& Hanrahan, 1998), which contains items referring to controllability, responsibility, and intentionality. Mantler, Schellenberg, and Page (2003) argued that controllability and responsibility are different constructs that are interlinked. For an individual to be perceived as responsible for a cause, he or she must initially be perceived as having control over it. Weiner (1985) argued that intentionality and controllability are different constructs. Compared with controllability, intentionality is not a property of a cause; intent describes an action. It is clear that controllability is linked to but not defined by responsibility or intentionality.

In the revised Causal Dimension Scale (CDSII; McAuley, Duncan, \& Russell, 1992), the controllability dimension was subdivided into personal control (control by the actor) and external control (control by others). Although the chi-square statistic for model fit was significant, $\chi^{2}(48)=96.85, p<.001$, McAuley et al. reported an adequate value for the goodness-of-fit index (.96) (Hu \& Bentler, 1999). In subsequent work, however, concerns have been raised regarding the factor structure of the CDSII. For example, Ingledew, Hardy, and Cooper (1996) found a poor fit for the CDSII with hospital workers in a failure condition, reporting relatively high values for the root mean square error of approximation $(.10, p<.004)$ and the standardized root mean square residual (.13). Similarly, Crocker et al. (2002) found poor fits for the CDSII across team and individual sports subsamples, and male and female subsamples, reporting relatively low values for the comparative fit index (values ranged from .87 to .92). Moreover, Ingledew et al. and Crocker et al. reported significant $(p<.01)$ correlations between personal control and locus of causality across success $(r=.36)$ and failure $(r=.49)$ conditions, and individual $(r$ $=.82)$ and team $(r=.91)$ sports subsamples, respectively. ${ }^{1}$ These high interfactor correlations suggest that there is some cause for concern regarding the discriminant validity of the subscales. Finally, it has been noted that the assessment of personal and external control is not congruent with Weiner's $(1979,1985)$ model, and that respondents have considerable problems understanding some items and the interpretation of scale anchors (Biddle \& Hanrahan, 1998; Biddle, Hanrahan, \& Sellars, 2001).

Coupled with a need for further instrument development (Crocker et al., 2002), there have been calls (Rees et al., 2005; Rejeski \& Brawley, 1983) for sport attribution research to consider alternative perspectives to that of Weiner $(1979,1985)$. In Rejeski and Brawley's review of the status of sport attribution research at that time, they criticized the unquestioning use of Weiner's model and urged a broader conceptual approach in future work. Rees et al. have subsequently proposed that research in sport should focus upon the main effects of controllability, together with 
the interactive effects of controllability and generalizability dimensions (stability, globality, and universality) upon outcomes such as self-efficacy. This proposal is underpinned by at least three key points that are briefly outlined here. First, reviewers of attribution research in sport psychology have suggested that controllability is a key dimension upon which attention should be focused (e.g., Biddle, 1993; Biddle et al., 2001; Hardy, Jones, \& Gould, 1996). Controllability is also considered the most important attribution dimension in the general social psychology research of Anderson and colleagues (e.g., Anderson \& Riger, 1991). Attributing an event to a controllable cause leads to expectations of control over events in the future. Moreover, the effect and importance of perceived uncontrollability is demonstrated in the learned helplessness literature (e.g., Abramson, Seligman, \& Teasdale, 1978). Abramson et al.'s reformulation of the learned helplessness model regards the expectancy of future uncontrollability to be the most direct determinant of helplessness.

In sport, controllability may also be of greater psychological significance than locus of causality. The positive associations often observed between controllability and locus of causality (e.g., Crocker et al., 2002; Ingledew et al., 1996; McAuley et al., 1992) suggest that people may feel there is much overlap between where a cause lies and by whom it is controlled. According to relapse prevention (Marlatt \& Gordon, 1985), following a lapse in some positive behavior, stable and uncontrollable attributions, whether they are internal or external, will lead to lowered selfefficacy and a greater probability of total relapse. Compared with locus of causality, controllability may therefore be a more important dimension to focus upon. In this article, we adopt a control-by-the-person definition of controllability. ${ }^{2}$

Second, whereas controllability relates to whether the cause is controllable or uncontrollable, the stability, globality, and universality dimensions are somewhat different, in that they deal with the generalizability of the cause of the event. As we have noted, stability refers to whether the cause will (unstable) or will not (stable) change over time. The addition of globality refers to whether the cause affects a wide range of situations with which the person is faced (a global attribution) or a narrow range of situations (a specific attribution); universality refers to whether the cause is common to all people (a universal attribution) or unique to the individual (a personal attribution) (Abramson et al., 1978; Rees et al., 2005). This leads to an expanded conceptualization of generalizability: In addition to whether causes generalize across time (stability), attribution research should examine whether causes generalize across situations (globality) and/or all people (universality).

Third, the focus of much attribution research has been upon main effects of attribution dimensions (e.g., Bond, Biddle, \& Ntoumanis, 2001; Gernigon \& Delloye, 2003). To model generalizability implies the need to consider interactive effects (see, e.g., Carver, 1989), but only a few studies (e.g., Ingledew et al., 1996) have employed this strategy. Interactions of attribution dimensions are important because, for example, attributing failures to uncontrollable causes may only lead to lower levels of self-efficacy, when causes are also considered to be stable (will not change over time), or global (affect a wide range of situations), or personal (unique to the individual). For example, a swimmer attributing his or her poor performance to a poor leg-kick action might say, "There is nothing I can do about it" (an uncontrollable attribution), together with "and it is not going to change" (a stable attribution), or "and this affects all aspects of my swimming" (a global 
attribution), or "and it is just me who has this problem" (a personal attribution). In this instance, the swimmer might well be expected to experience lower levels of self-efficacy for subsequent performance. Conversely, higher levels of self-efficacy would be expected if the swimmer were to combine his or her uncontrollable attribution with "but this will change" (an unstable attribution), or "however, this only affects my breast stroke" (a specific attribution), or "but everyone struggles with aspects of their technique at some point" (a universal attribution).

In general, attribution research has focused upon attributions following negative and positive events (Weiner, 1985), and in sport, subjective perceptions of success rather than objective performance (losing and winning) have been used to distinguish between negative and positive events (e.g., Biddle, 1993; Bond et al., 2001; McAuley, 1985). The primary focus of the present paper is upon less (least) successful performances. The rationale for this decision is that although individuals formulate attributions following less and more successful performances (Biddle \& Hanrahan, 1998), there is support to suggest that the attribution process is more salient following less successful performances (Vallerand, 1987; Wong \& Weiner, 1981). Consequently, relationships between attributions and outcomes might be more evident following less successful performances.

This article reports three studies. In Study 1, we examined the factor structure of an attributions measure assessing the dimensions of controllability, stability, globality, and universality (the CSGU) across least successful and most successful conditions. In Study 2, following less successful performances, we tested the factor structure of the CSGU with an independent sample, together with examining correlations between the CSGU dimensions and the CDSII dimensions. Although, as we have highlighted, there are concerns over the use of the CDSII as a measurement instrument (Biddle \& Hanrahan, 1998; Biddle et al., 2001; Crocker et al., 2002), the CDSII currently remains the most widely used state attribution measure. It was hypothesized that the CSGU controllability subscale and the CDSII personal control subscale would be positively correlated, and the CSGU stability subscale and the CDSII stability subscale would be positively correlated. In Study 3, following less successful performances, we used the CSGU to examine the main and interactive effects of attributions upon subsequent self-efficacy. It was predicted that attributions to controllable causes would lead to higher subsequent self-efficacy. As we have suggested, however, the effects of controllability might be moderated by generalizability attributions. Exploratory tests, therefore, were conducted to examine the interactive effects of controllability and the three generalizability dimensions of stability, globality, and universality upon subsequent self-efficacy.

\section{Study 1}

\section{Method}

\section{Initial Scale Construction}

The CSGU, constructed by the two study authors and another expert in sport psychology, initially contained 24 items to assess the four dimensions of controllability, stability, globality, and universality (see Appendix). Response options for each item ranged from 1 (not at all) to 5 (completely), with higher values representing items 
that were more controllable, stable, global, and universal. Items were prefixed with the question, "In general, to what extent is your reason something that. . .." Before data collection, the 24 items were assessed for content validity by 12 independent judges (mean age 23.17 years, $S D 1.40$ ), all of whom had completed postgraduate modules detailing attribution theory, psychometric measurement, and quantitative research methods. The judges were required to read each item, and then circle the attribution dimension to which they felt the item belonged (Dunn, Bouffard, \& Rogers, 1999; Sudman, Bradburn, \& Schwarz, 1996). Of the 24 items, 23 were correctly assigned to dimensions by at least 11 of the judges. The controllability item "you could influence in the future" was incorrectly described as a stability or globality item by four of the judges. Consequently, the item was removed, resulting in a 23-item measure to assess the four dimensions of controllability (five items), stability (six items), globality (six items), and universality (six items).

\section{Participants}

Participants were 210 (111 female, 99 male; mean age 20.01, SD 1.53 years) sport and health science undergraduate students at a university in southwest England. All participants were Caucasian British citizens. Participants competed in a variety of team $(n=116)$ and individual $(n=94)$ sports. The performance level of the participants ranged from club $(n=102)$ through county $(n=53)$, regional $(n=30)$, national $(n=17)$, and international $(n=7)$ level.

\section{Procedure}

The construct validity of the attributions measure in this study was examined for participants" "least successful" and "most successful" performances within the past 3 months. Ethical approval was granted by a university ethics committee and participants provided informed consent. Participants were asked to remember their least successful performance within the past 3 months (Condition 1) before answering the following question: "To what extent was this performance successful?" Response options ranged from 1 (not at all) to 5 (completely). With this performance in mind, an open-ended statement required participants to write down the single most important reason for how they performed. In relation to this reason, participants completed the CSGU. Participants repeated this procedure for their most successful performance within the past 3 months (Condition 2).

\section{Analyses}

The construct validity of the CSGU could be tested using exploratory factor analysis or confirmatory factor analysis. Although the number of factors can be specified in advance with exploratory factor analysis, it is not possible to force items to load only on certain factors. Conversely, confirmatory factor analysis is generally based on a strong theoretical foundation that allows the researcher to specify a factor model in advance and subsequently force items to load on specific factors (Jöreskog, 1993; Jöreskog \& Sörbom, 1996; Schutz \& Gessaroli, 1993). In the current study, items were developed to assess specific factors (i.e., attribution dimensions); it seemed sensible, therefore, to assess the fits of data to models in which items were forced to load on specific factors. 
The factor structure of the CSGU was tested using confirmatory factor analysis (CFA) with maximum likelihood estimation (Jöreskog \& Sörbom, 1996). Data analyses using LISREL 8.30 (2000) were conducted separately for the two conditions. The sequential model testing approach, as recommended by Jöreskog (1993) was employed. This involves three stages. First, tests of separate single-factor models corresponding to individual subscales were performed, the purpose of which was to assess the convergent validity of the items making up each subscale. As well as the overall goodness of fit of the models, the completely standardized factor loadings (loadings with values for $z$ above 1.96 were considered significant), the standardized residuals (values above 2 and below -2 were considered large), and the modification indices for the covariances between measurement errors (values above 7 were considered large) were examined (Jöreskog \& Sörbom, 1996). For example, a large positive standardized residual between two items would suggest that these items share more in common than the model allows; a large negative standardized residual between two items would suggest that these items share less in common than the model allows. Similar diagnostic information is provided by the modification indices for the covariances between measurement errors. Second, tests of each pair of subscales were performed, combining them in two-factor models. The first purpose of this stage was to identify ambiguous items. Large modification indices would suggest that improvements in fit could be expected if items were freed to cross-load on another factor. The second purpose was to investigate the discriminant validity of the factors. This was achieved by examining the $95 \%$ confidence interval $( \pm 1.96 \mathrm{SE})$ around each correlation between factors. A confidence interval including 1.0 would suggest that the factors were perfectly correlated and therefore lacked discriminant validity. The diagnostic information from the single-factor and two-factor stages was used to aid the process of scale refinement (item deletion) and further model testing. Finally, all factors were included in a full model.

The full four-factor model was tested for factorial invariance across conditions. As data were collected on one sample, a within-subject design was employed, testing invariance in one CFA by allowing corresponding factors, items, and error variances to covary (see, e.g., Raykov, 2006). CFA models fit to the data included configural, measurement, and structural factorial invariance models (see Byrne, 1998, 2006).

The goodness of fit of the models was tested using the chi-square likelihood ratio statistic ( $\chi^{2}$, used as a subjective index of fit; Jöreskog \& Sörbom, 1989), the root mean square error of approximation (RMSEA; Steiger, 1990) and its associated $p$-value (for RMSEA < .05), the standardized root mean square residual (SRMR), the comparative fit index (CFI; Bentler, 1990), and the non-normed fit index (NNFI; Tucker \& Lewis, 1973). These fit indices included measures from three different classes (absolute fit, absolute fit with penalty function, and incremental/comparative fit) (Hu \& Bentler, 1999; Jöreskog, 1993; Jöreskog \& Sörbom, 1996). The recommendations for fit of $\mathrm{Hu}$ and Bentler are values for SRMR close to .08, RMSEA close to .06 (Browne \& Cudeck, 1993, suggested that values up to .08 indicate a reasonable error of approximation, but models with values greater than .10 would be unacceptable), and CFI and NNFI close to $.95 .^{3}$ An alpha level of .05 was used for all statistical tests. 


\section{Results}

The data were screened for outliers, missing values, and indices of non-normality. There was a significant difference, $t(209)=40.67, p<.01$, between participants' perceptions of their least successful $(M=1.52, S D=.64)$ and most successful $(M$ $=4.19, S D=.65$ ) performances within the past 3 months. The factor structure of the CSGU was tested across least successful and most successful conditions.

\section{Least Successful Condition}

At the single-factor stage, one item was removed from the controllability subscale and two items were removed from the stability, globality, and universality subscales (total of seven items removed) (Table 1). Although all factor loadings were significant, items were removed because of large standardized residuals with other items in the subscale. All chi-square statistics for model fits were nonsignificant, RMSEA values ranged from .00 to .08 (all were nonsignificant), SRMR values from .01 to .02 , and NNFI from .99 to 1.01. Comparative fit index values were 1.00. Factor loadings ranged from .70 to .91 , except for the factor loading of .42 for the stability item "does not fluctuate across performances."

At the two-factor stage (Table 2), all chi-square statistics for model fits were nonsignificant, RMSEA values ranged from .02 to .05 (all were nonsignificant), SRMR values from .03 to .04, CFI from .99 to 1.00 , and NNFI from .98 to .99 . The $95 \%$ confidence interval around two-factor intercorrelations ranged from .10 to .47 .

At the full four-factor model stage (Table 3), although the chi-square statistic was significant, $\chi^{2}(98)=129.88, p<.05$, the RMSEA was low (.04), with a nonsignificant test for close fit, the SRMR was low (.04), and the CFI (.98) and NNFI (.98) were high. These values are indicative of good fit (Hu \& Bentler, 1999). Coefficient alpha reliabilities for the four subscales ranged from .81 to .91. Following confirmatory factor analysis, Shook, Ketchen, Hult, and Kacmar (2004) recommended composite reliability, which draws on the standardized loading and measurement error for each item. ${ }^{4} \mathrm{~A}$ value below .70 indicates poor composite reliability (Shook et al., 2004). Composite reliabilities ranged from .83 to .92 . Shared variance measures the amount of variance captured by the factor in relation to the amount of variance due to measurement error. ${ }^{5} \mathrm{~A}$ value below .50 indicates that the variance due to measurement error is larger than the variance captured by the factor (Fornell \& Larcker, 1981), and the content validity of the items, as well as the factor is questionable. Shared variance for the four factors ranged from .57 to .73 . The completely standardized solution for the full four-factor model is presented in Table 3.

\section{Most Successful Condition}

The four-factor model identified in the least successful condition was tested for fit using data from the most successful condition. The completely standardized solution for the full four-factor model is presented in Table 4. Although the chi-square statistic was significant, $\chi^{2}(98)=129.49, p<.05$, the RMSEA was low (.04), with 


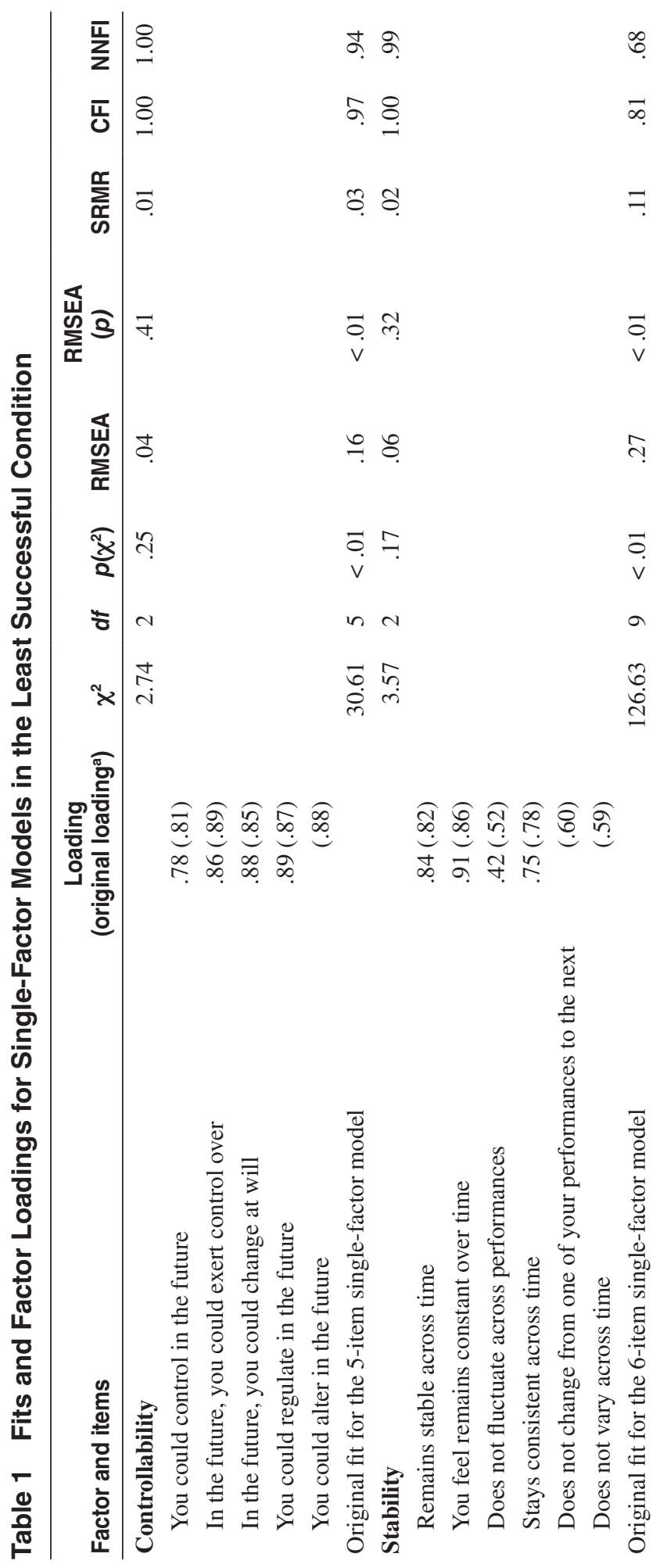




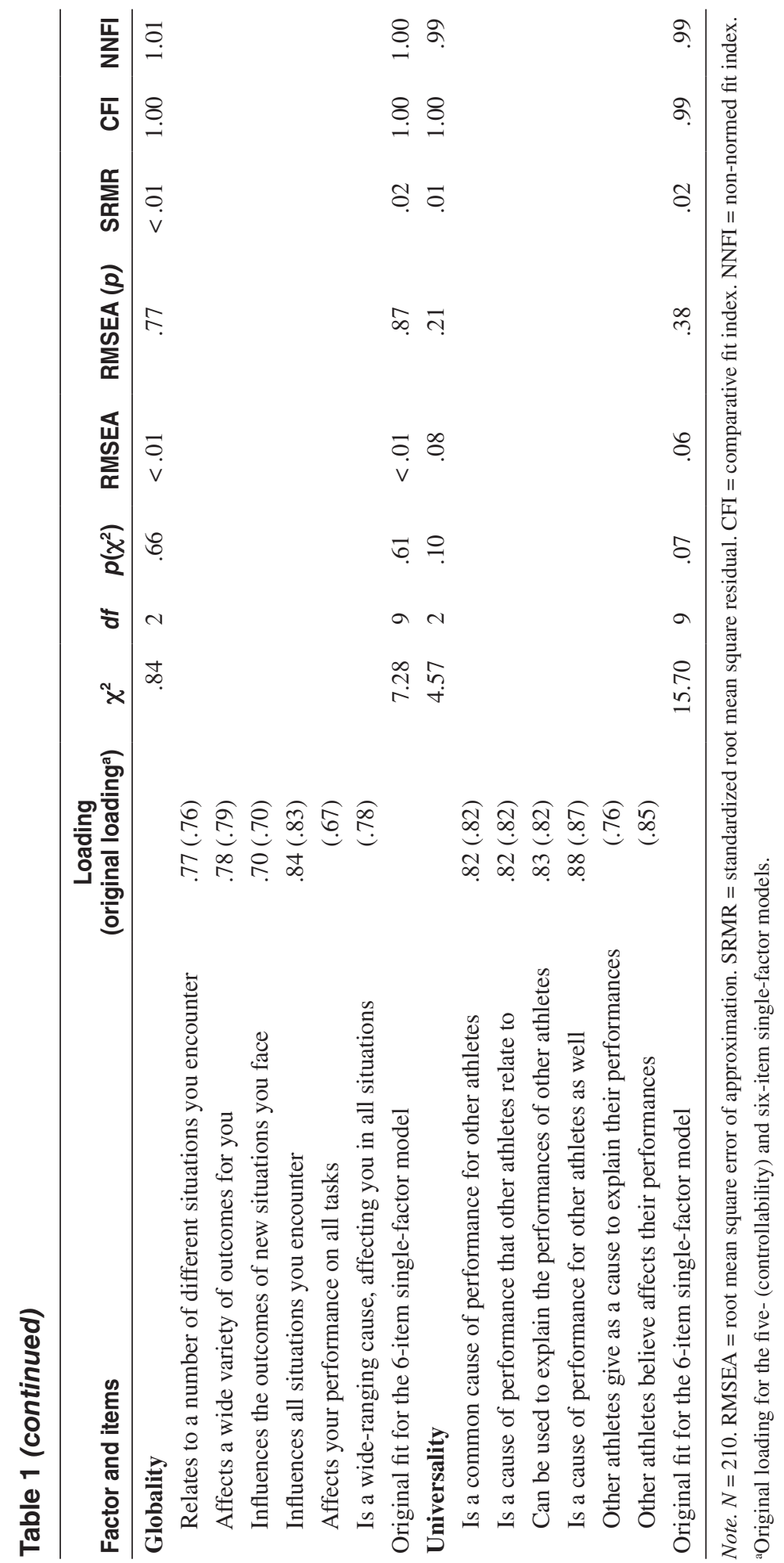




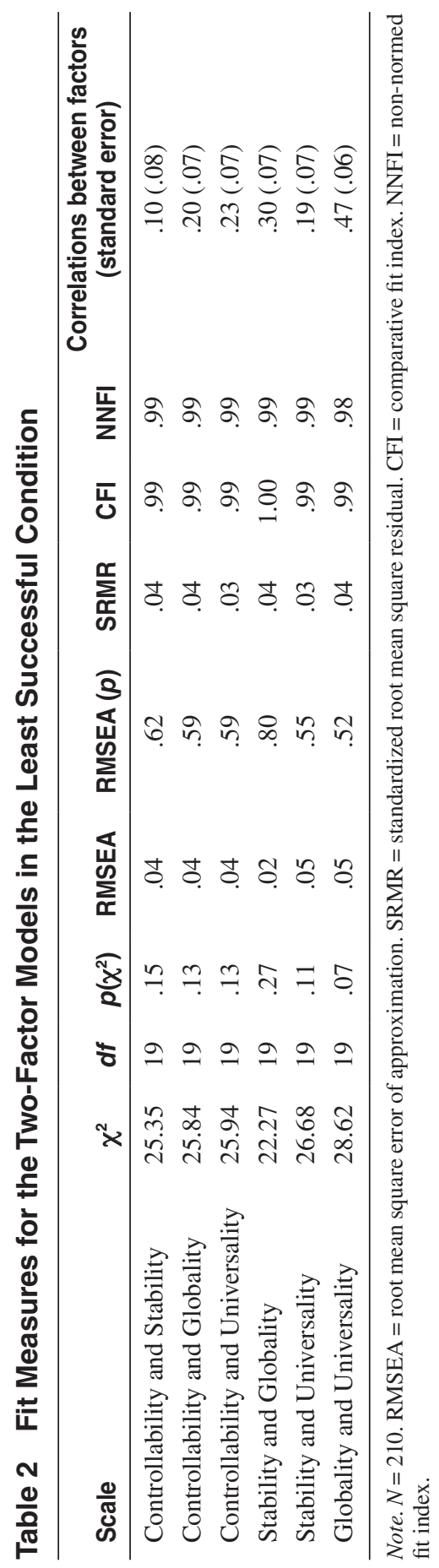




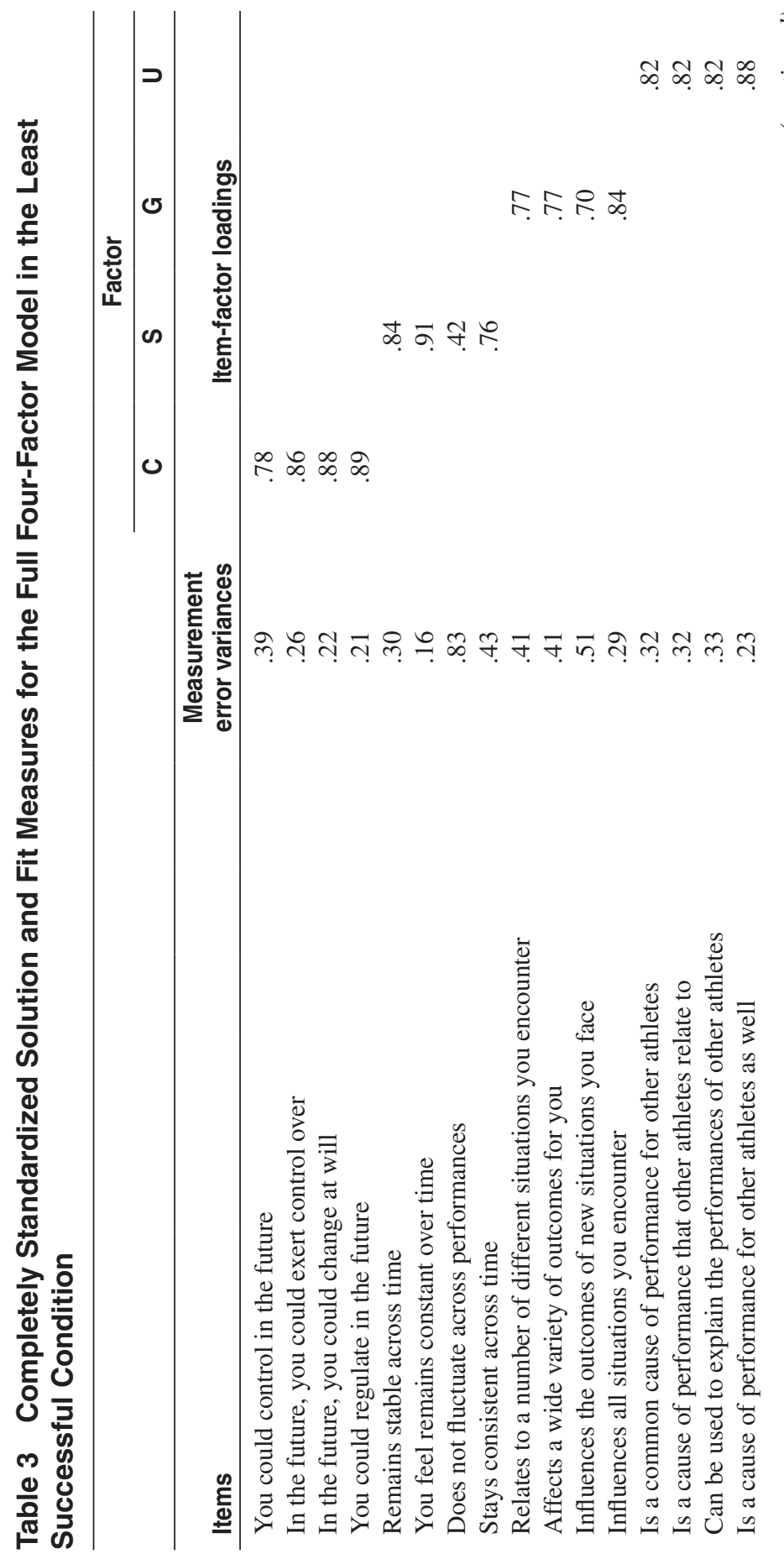




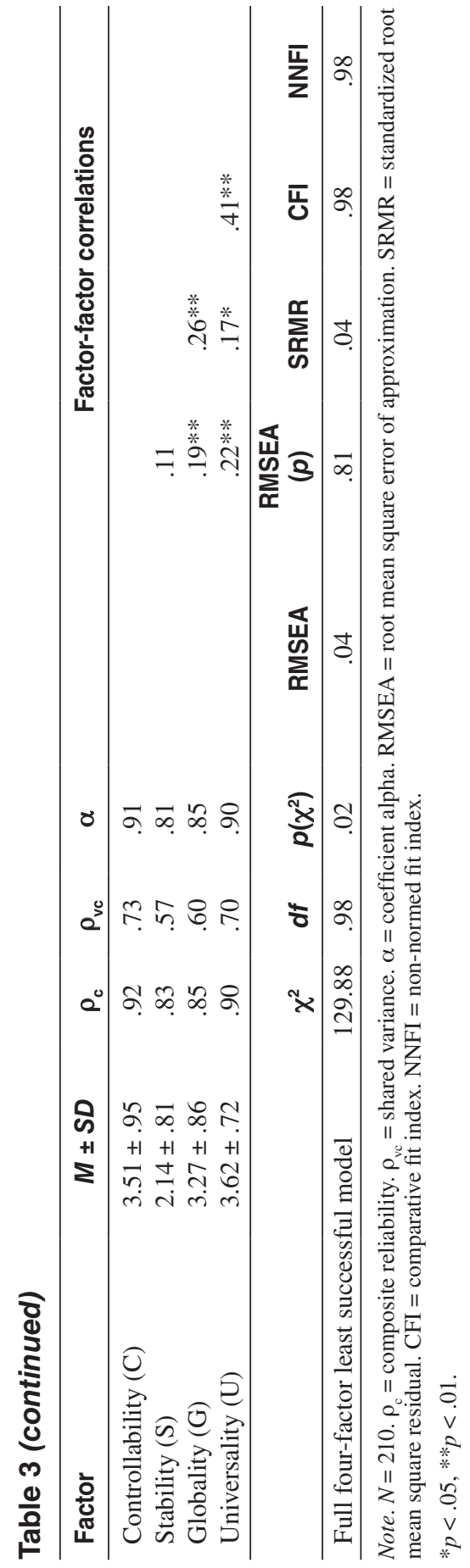




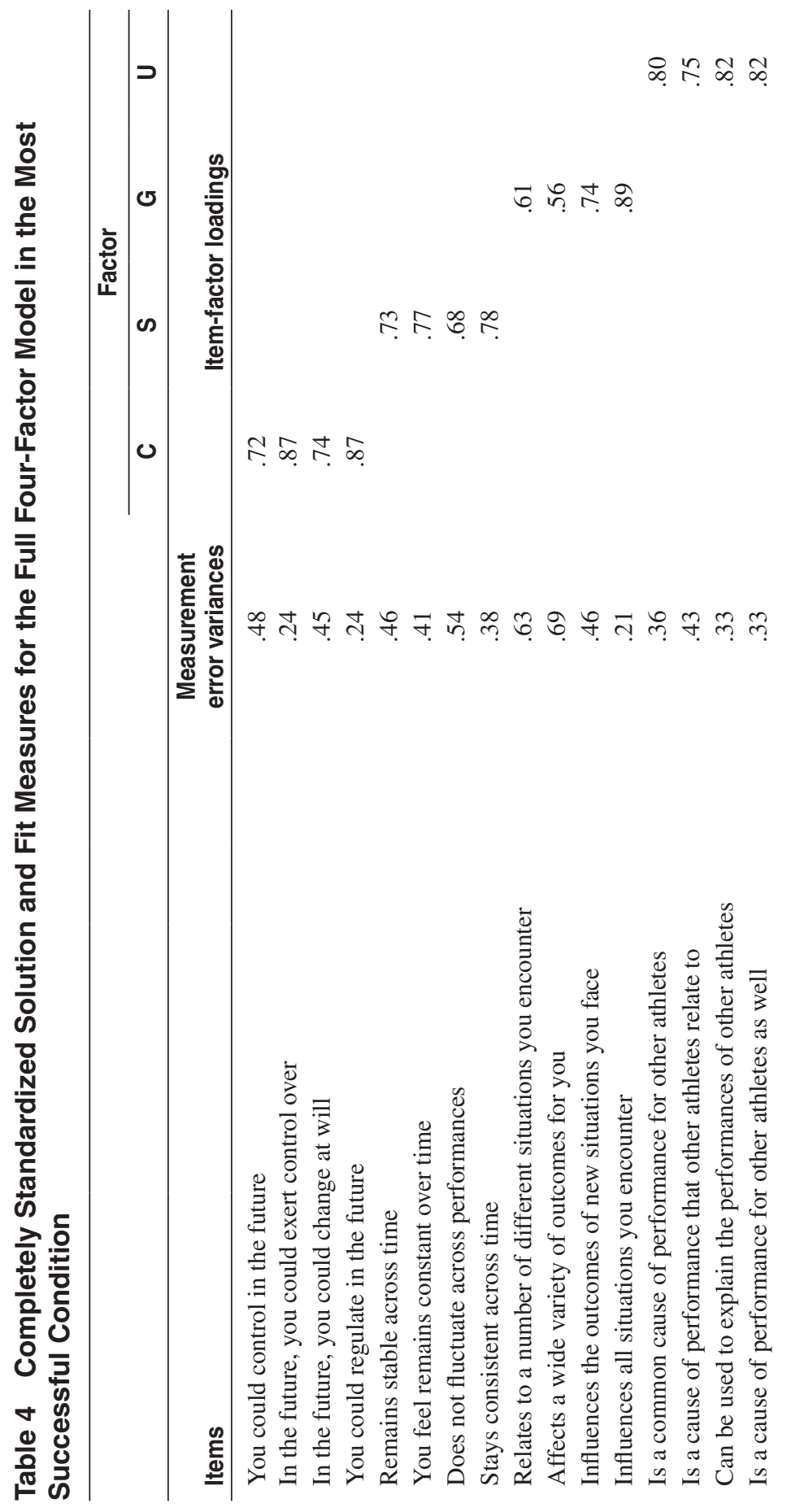




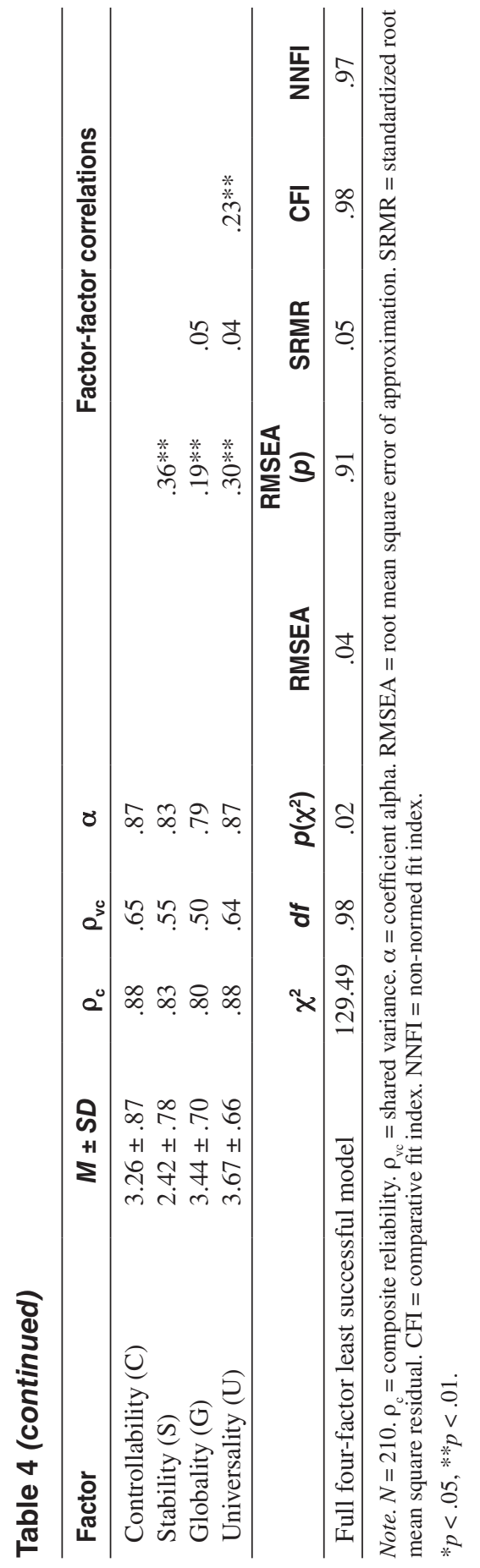


a nonsignificant test for close fit, the SRMR was low (.05), and the CFI (.98) and NNFI (.97) were high. These values are indicative of good fit (Hu \& Bentler, 1999). Coefficient alpha reliabilities ranged from .79 to .87 , composite reliabilities from .80 to .88 , and shared variance from .50 to .65 .

\section{Factorial Invariance}

First, an eight-factor model of covariance structures allowing corresponding factors, items, and error variances to covary was fitted to the data. This model (baseline model) imposed no equality constraints on parameter estimates across conditions. The model fit provided evidence for configural factorial invariance, $\chi^{2}(432)=$ 564.95, $p<.01$; RMSEA = .04, $p=1.00 ;$ SRMR = .07; and CFI and NNFI = .96. The second model tested for measurement factorial invariance, constraining corresponding factor loadings to be equal across conditions. Although there was a significant change in the value for chi-square, $\Delta \chi^{2}(16)=58.38, p<.01$, there was only a negligible change in the value for CFI $(\Delta \mathrm{CFI}=-.01)$ and the overall model exhibited a good fit to the data (RMSEA $=.04, p=.95 ; \mathrm{SRMR}=.08$; NNFI $=$ $.95) .{ }^{6}$ The third model tested for structural factorial invariance, constraining corresponding factor loadings and factor covariances to be equal across conditions. Although there was a significant change in the value for chi-square, $\Delta \chi^{2}(22)=$ 78.96, $p<.01$, there was only a negligible change in the value for CFI $(\Delta \mathrm{CFI}=$ $-.01)$ together with an adequate overall fit for the model to the data (RMSEA = $.04, p=.94 ;$ SRMR $=.09 ; \mathrm{NNFI}=.94)$.

\section{Discussion}

The factor structure of the CSGU was confirmed across least successful and most successful conditions. Across conditions, factor correlations for the CSGU ranged from .04 to .41 , and factor loadings ranged from .56 to .91 for all models except for one item. The factor loading of the stability item "does not fluctuate across performances" was .42 in the least successful condition. Although low, the loading was significant $(z=5.98, p<.01)$ and modification indices were low (highest modification index was 1.70 to cross-load on controllability); consequently, the item was retained. The low factor loading might have been the result of the negative wording of the item (see Streiner \& Norman, 1995). In Studies 2 and 3 of the present article, the item is reworded "fluctuates across performances" and reverse scored. Across conditions, factorial invariance analyses provided evidence of configural, measurement, and structural factorial invariance. In summary, the results of Study 1 provide initial support for the factor structure of the CSGU. 


\section{Study 2}

\section{Method}

\section{Participants}

Participants were 225 (114 male, 111 female; mean age 22.83, SD 8.40 years) competitive athletes, of which the majority $(n=183)$ were not university students. All participants were Caucasian British citizens. Participants competed in a variety of team $(n=118)$ and individual $(n=107)$ sports. The performance level of the participants ranged from club $(n=69)$ through county $(n=54)$, regional $(n=42)$, national $(n=34)$, and international $(n=26)$ level.

\section{Procedure}

Ethical approval was granted by a university ethics committee and participants provided informed consent. Sampling was opportunistic, with participants recruited at the site of competitions. Data were collected $1 \mathrm{hr}$ after performance (e.g., a soccer match or a tennis match) to give participants a chance to physically recover from competition. Participants were asked, "To what extent was this performance successful for you?" with response options ranging from 1 (not at all) to 5 (completely). Participants with response options 1 and 2 were selected for the study $(N=225)$; participants with responses ranging from 3 to 5 were debriefed and took no further part in the study. An open-ended statement required participants to write down the single most important reason for how they performed. In relation to this reason, participants completed two measures of attributions. The measures of attributions were presented in a random order to participants.

\section{Measures}

Participants were asked to complete two measures of attributions: the CSGU developed in Study 1 and the CDSII (McAuley et al., 1992). The CSGU consists of 16 items assessing the four attribution dimensions of controllability, stability, globality, and universality. From the results of Study 1, the stability item "does not fluctuate across performances" was reworded "fluctuates across performances" and reverse scored. The CDSII comprises 12 items assessing the four subscales (three items per subscale) of locus of causality, stability, personal control, and external control. Examples of items are as follows: "that reflects an aspect of yourself-reflects an aspect of the situation" (locus of causality), "permanent-temporary" (stability), "manageable by you - not manageable by you" (personal control), and "over which others have control—over which others have no control" (external control). Participants' responses are recorded on a 1-to-9 bipolar scale. Subscale scores range from 3 to 27, with higher values representing attributions that are more internal, stable, personally controllable, and externally controllable. McAuley et al. reported 
coefficient alpha reliabilities for the four dimensions as follows: locus of causality .60-.71, stability .66-.68, personal control .72-.90, and external control .71-.92. In the current study, values ranged from .76 to .87 (see Table 5).

\section{Analyses}

The factor structure of the CSGU was tested using confirmatory factor analysis with maximum likelihood estimation. For model fit, we examined the same measures of fit reported in Study 1. Correlations were used to determine relationships between measures. An alpha level of .05 was used for all statistical tests.

\section{Results}

The data were screened for outliers, missing values, and indices of nonnormality. A good fit was observed for the CSGU to the data. Although the $\chi^{2}$ statistic was significant, $\chi^{2}(98)=136.39, p<.05$, the RMSEA was low (.04) with a nonsignificant test for close fit, the SRMR was low (.05), and the CFI (.98) and NNFI (.97) were high. Composite reliabilities ranged from .83 to .88 , and shared variance from .54 to .65 .

Means, standard deviations, coefficient alpha reliabilities, and correlations of attribution dimensions are reported in Table 5. Coefficient alpha reliabilities were satisfactory (i.e., $\geq .70$, Nunnally, 1978) for all scales. Within measures, correlations between factors ranged from low to moderate (.10 to .51 for the CSGU, and -.35 to .59 for the CDSII). Across measures, correlations between factors ranged from -.24 to .67 . The relationships predicted in the hypotheses were significant and in the predicted direction: The controllability subscale of the CSGU was significantly and positively associated with the personal control subscale of the CDSII ( $r=.62$, $p<.01$ ), and the stability subscale of the CSGU was significantly and positively associated with the stability subscale of the CDSII $(r=.67, p<.01)$.

\section{Discussion}

The results provide evidence to support the study hypotheses: The controllability and stability subscales of the CSGU were significantly and positively associated with the personal control and stability subscales of the CDSII, respectively. Collectively, the results provide further evidence of construct validity for the CSGU: Further support was provided for the factor structure of the CSGU with an independent sample, together with initial evidence of concurrent validity for the controllability and stability subscales of the CSGU. Although Studies 1 and 2 provide strong support for the factor structure of the CSGU, the potential theoretical and applied advancements for examining an expanded conceptualization of generalizability, together with examining interactive effects of attribution dimensions have not been demonstrated. These issues are addressed in Study 3. 


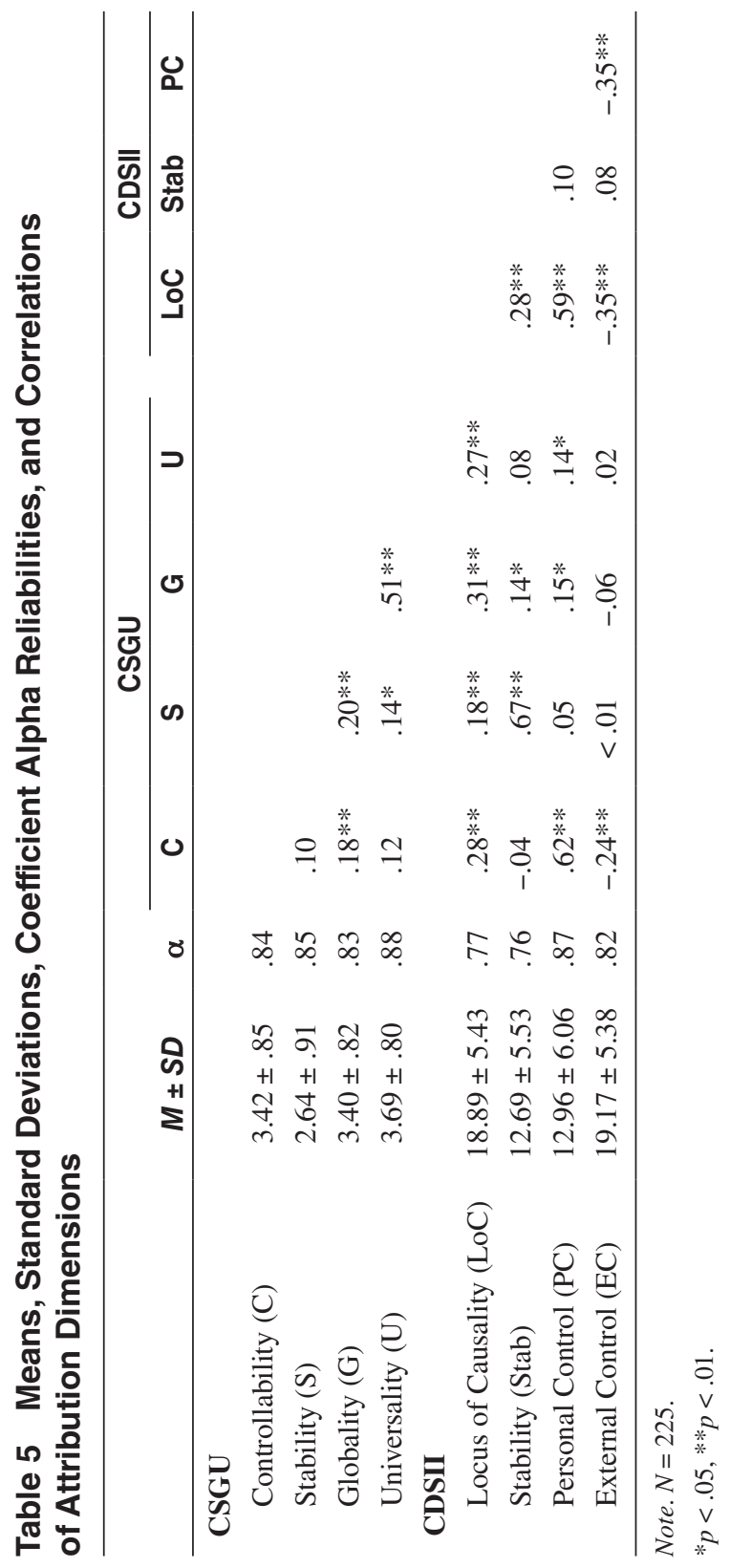




\section{Study 3}

\section{Method}

\section{Participants}

Participants were 100 (77 male, 23 female; mean age 20.60, SD 1.86 years) competitive road cyclists. All participants were Caucasian British citizens. The standard of performance of the participants ranged from second $(n=20)$ through first $(n=$ $42)$ and elite $(n=38)$ categories for British cycling.

\section{Procedure}

Ethical approval was granted by a university ethics committee and participants provided informed consent. Sampling was opportunistic, with participants recruited at the site of competitions. Data were collected at three time points. At Time 1 (Day 1), $1 \mathrm{hr}$ before performance (to allow participants time to prepare for the race), participants completed a six-item measure of self-efficacy relating to an up-coming race. This was regarded as participants' precompetition self-efficacy. At Time 2 (Day 1), $1 \mathrm{hr}$ after performance (to give participants a chance to physically recover from competition), participants were asked, "To what extent was this performance successful for you?" with response options ranging from 1 (not at all) to 5 (completely). Participants with response options 1 and 2 were selected for the study $(N$ $=100$ ); participants with responses ranging from 3 to 5 were debriefed and took no further part in the study. An open-ended statement required participants to write down the single most important reason for how they performed. In relation to this reason, participants completed a measure of attributions. At Time 3 (Day 8), $1 \mathrm{hr}$ before performance (to allow participants time to prepare for the race), participants completed a six-item measure of self-efficacy relating to an up-coming race (note, performances at Times 1 and 3 were successive). This was regarded as participants' subsequent self-efficacy.

\section{Measures}

Attributions. The CSGU measure of attributions used in Study 2 was used in the current study. In the current study, coefficient alpha reliabilities for the four scales were satisfactory (i.e., $\geq .70$, Nunnally, 1978) ranging from .77 to .81 .

Self-Efficacy. In relation to an up-coming race, participants completed a six-item measure of self-efficacy, defined as the "beliefs in one's capabilities to organize and execute the courses of action required to produce given attainments" (Bandura, 1997, p. 3). Based upon this definition, items were developed that reflected components of cycling performance. As self-efficacy is an assessment of perceived capability, items were phrased in terms of can do rather than will do, and references were made to barriers (e.g., perform well, even if things get tough) to successful performance (see Bandura, 1997) or characteristics that may lead to a successful performance (e.g., recover quickly after a sprint). Items were preceded by the statement, "With reference to today's race, to what extent do you feel confident that you can ..." with response options ranging from 1 (not at all) to 5 (completely). The items were 
"recover quickly after a sprint"; "work effectively with your competitors to gain ground;" "raise the level of your performance if you have to"; "employ appropriate tactics for the race"; "anticipate a sprint from the front of a group"; and "perform well, even if things get tough." The mean score of the six items was taken to indicate participants' self-efficacy. Coefficient alpha reliabilities for the six-item scale were .89 for precompetition self-efficacy and .90 for subsequent self-efficacy.

\section{Analyses}

Moderated hierarchical regression analyses (Jaccard, Turrisi, \& Wan, 1990) were used to examine the effects of attributions upon the change in self-efficacy. In the hierarchical regression analyses, the dependent variable was subsequent selfefficacy and the effect of precompetition self-efficacy was controlled by entering it on the first step of the regression equation (see, e.g., Gernigon \& Delloye, 2003). Following precompetition self-efficacy, measures of attributions were entered in a two-step process to examine main and interactive effects. First, controllability, stability, globality, and universality were entered (main effects); second, the interaction terms for controllability and stability, controllability and globality, and controllability and universality were entered. Based upon the theoretical perspective of this article that controllability is a key dimension upon which attention should be focused, interactions between generalizability dimensions were not examined. The significance of increments in explained variance $\left(\Delta R^{2}\right)$ in subsequent self-efficacy over and above the variance accounted for by those variables already entered into the equation, as well as the sign of the regression coefficients $(b)$, was then assessed at each step. Jaccard et al. emphasized that the independent variables should be centered before the formation of product terms. In this study's analyses all the independent variables were standardized (with a mean of 0 and standard deviation of 1), thereby centering them, before any interactive terms were computed, and the unstandardized solution was then examined. An alpha level of .05 was used for all statistical tests.

\section{Results}

The data were screened for outliers, missing values, and indices of nonnormality. Means, standard deviations, coefficient alpha reliabilities, and correlations for all scales are reported in Table 6. The results of the hierarchical regression analyses are reported in Table 7. Precompetition self-efficacy was a significant predictor of subsequent self-efficacy $\left(R^{2}=.54, b=.57, \beta=.77, s r=.75, p<.01\right)$. Over and above the variance accounted for by precompetition self-efficacy, there were significant main effects upon subsequent self-efficacy $\left(\Delta R^{2}=.10, p<.01\right)$, primarily attributable to controllability $(b=.23, \beta=.31, s r=.26, p<.01)$, globality $(b=$ $-.16, \beta=-.21, s r=-.17, p<.01)$, and universality $(b=.17, \beta=.23, s r=.19, p<$ $.01)$. These results suggest that following less successful performances, participants had higher subsequent self-efficacy when they viewed causes of performance as controllable, and/or specific, and/or universal.

Over and above the variance accounted for by precompetition self-efficacy and the main effects, there was a significant interactive effect upon subsequent self-efficacy $\left(\Delta R^{2}=.06, p<.01\right)$, primarily attributable to the interaction between 
controllability and stability $(b=.12, \beta=.20, s r=.19, p<.01$; Figure 1$)$. Figure 1a demonstrates that following less successful performances, if causes were perceived to be stable (stability $+1 S D$ above its mean), higher levels of controllability were associated with higher levels of subsequent self-efficacy, $t=5.58, p<.01$; the slope for stability $-1 S D$ was nonsignificant, $t=1.66, p>.05$. Figure $1 \mathrm{~b}$ demonstrates

Table 6 Means, Standard Deviations, Coefficient Alpha Reliabilities, and Correlations of Attribution Dimensions and Self-Efficacy

\begin{tabular}{lrrrrrrr}
\hline & $\boldsymbol{M} \pm \mathbf{S D}$ & $\boldsymbol{\alpha}$ & $\mathbf{C}$ & $\mathbf{S}$ & $\mathbf{G}$ & $\mathbf{U}$ & PS \\
\hline Controllability (C) & $3.50 \pm .69$ & .77 & & & & & \\
Stability (S) & $2.75 \pm .71$ & .78 & $.28^{* *}$ & & & & \\
Globality (G) & $3.42 \pm .68$ & .78 & $.25^{*}$ & .05 & & & \\
Universality (U) & $3.70 \pm .64$ & .81 & .19 & .06 & $.50^{* *}$ & & \\
Precompetition Self-efficacy (PS) & $3.66 \pm .64$ & .89 & -.09 & .09 & $<.01$ & -.09 & \\
Subsequent Self-efficacy (SS) & $3.56 \pm .74$ & .90 & .19 & .18 & .01 & .11 & $.73^{* *}$ \\
\hline
\end{tabular}

Note. $N=100$.

$* p<.05, * * p<.01$.

Table 7 Main and Interactive Effects of Attributions Upon SelfEfficacy; Dependent Variable: Subsequent Self-Efficacy

\begin{tabular}{|c|c|c|c|c|c|}
\hline Step & & $\Delta R^{2 a}$ & $\begin{array}{c}b^{b} \\
\text { (standard error) }\end{array}$ & $\beta^{c}$ & $s r^{d}$ \\
\hline 1 & Precompetition Self-efficacy & $.54 * *$ & $.57 * *(.04)$ & .77 & .75 \\
\hline \multirow[t]{5}{*}{2} & Main effects & $.10 * *$ & & & \\
\hline & Controllability & & $.23 * *(.05)$ & .31 & .26 \\
\hline & Stability & & $<.01 \quad(.05)$ & $<.01$ & $<.01$ \\
\hline & Globality & & $-.16 * *(.05)$ & -.21 & -.17 \\
\hline & Universality & & $.17 * *(.05)$ & .23 & .19 \\
\hline \multirow[t]{4}{*}{3} & Interactive effects & $.06^{* *}$ & & & \\
\hline & Controllability $\times$ Stability & & $.12 * *(.04)$ & .20 & .19 \\
\hline & Controllability $\times$ Globality & & $.09 \quad(.05)$ & .16 & .11 \\
\hline & Controllability $\times$ Universality & & $(.06)$ & -.12 & -.08 \\
\hline
\end{tabular}

Note. $N=100$. All variables standardized except for interactive terms. Interactive terms formed from preceding (standardized) variables.

aStepwise change in $R^{2}$. bunstandardized regression coefficient in final equation. 'Standardized regression coefficient in final equation. ${ }^{\mathrm{d} S e m i p a r t i a l}$ correlation in final equation.

$* p<.05, * * p<.01$. 
(a)

$\cdots \ldots$ Low Stability $(-1)-$ High Stability $(+1)$

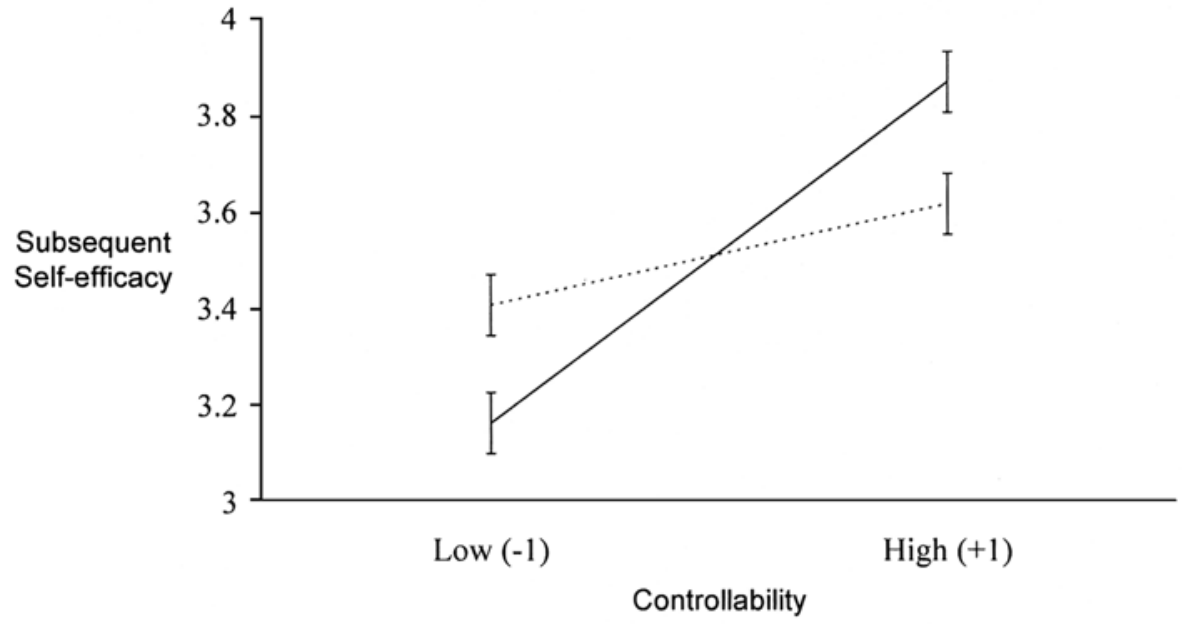

(b)

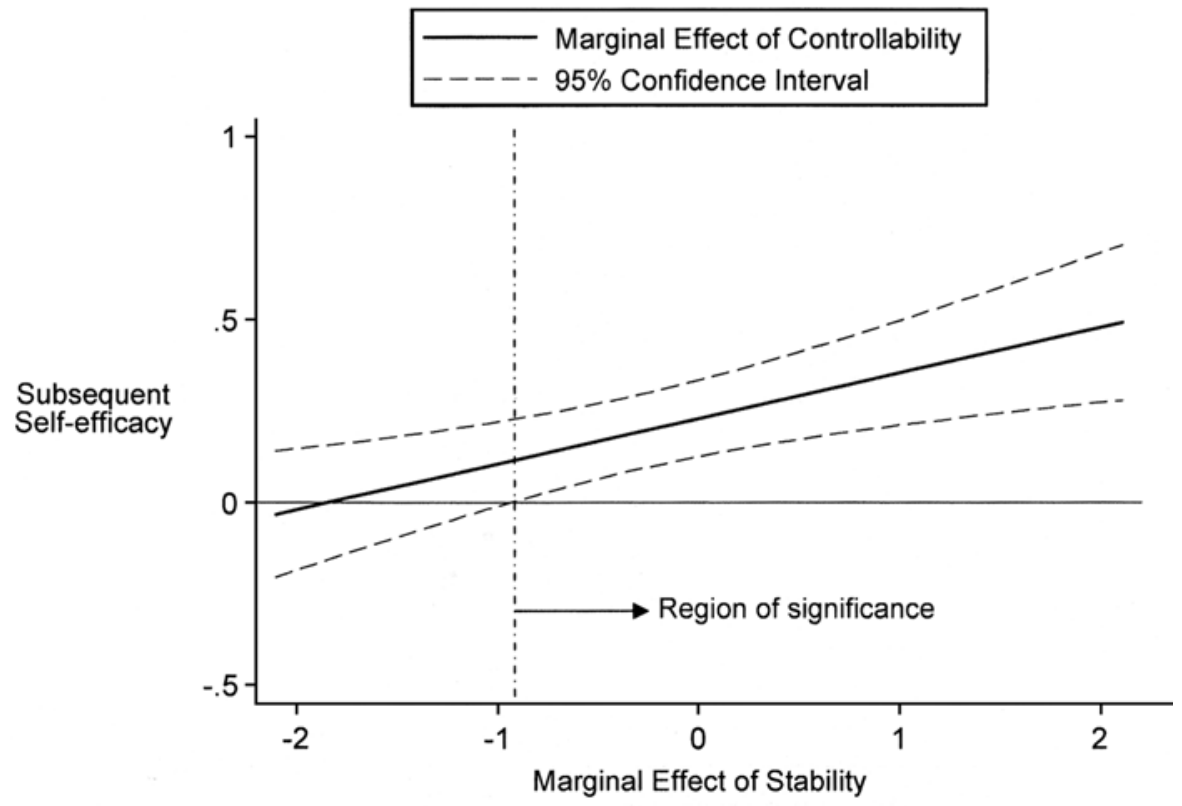

Figure 1 - The interactive effect for controllability and stability upon subsequent selfefficacy. 
that the effect of controllability upon subsequent self-efficacy was significant at relatively low to high levels of stability ( $\geq-.87 S D$ in the level of stability). ${ }^{7}$

\section{Discussion}

The results provide evidence to support the study hypotheses: Controllability was a significant predictor of self-efficacy, and stability (a generalizability dimension) moderated this effect. There were also main effects for globality and universality upon self-efficacy. Collectively, these results provide support for propositions that (a) controllability is an important attribution dimension (e.g., Anderson \& Riger, 1991; Biddle, 1993; Biddle et al., 2001; Hardy et al., 1996), (b) sport attribution research should examine alternative perspectives to that of Weiner's $(1979,1985)$ model (e.g., Rees et al., 2005; Rejeski \& Brawley, 1983), and (c) attribution research should move beyond examining main effects of attribution dimensions to exploring interactive effects (e.g., Rees et al., 2005). Indeed, these results demonstrate the potential theoretical and applied advantages for examining an expanded conceptualization of generalizability dimensions, together with interactive effects of attribution dimensions.

\section{General Discussion}

Having highlighted concerns regarding the CDSII and the passive acceptance of Weiner's $(1979,1985)$ model to sport attribution research, this article presented three studies that collectively provide initial evidence of construct validity for a novel four-factor measure of attributions. Study 1 reported good fits for the CSGU across most successful and least successful conditions. Study 2, following less successful performances, reported good fits for the CSGU with an independent sample, together with reporting significant relationships between the controllability and stability subscales of the CSGU and the personal control and stability subscales of the CDSII, respectively. Study 3, following less successful performances, reported significant main effects for controllability, globality, and universality, and a significant interactive effect for controllability and stability upon self-efficacy.

In Study 1, the factor structure of the CSGU, assessing the four dimensions of controllability, stability, globality, and universality, was confirmed across least successful and most successful conditions. For the full four-factor models, although the chi-square statistics were significant, values for RMSEA and SRMR were low, and values for CFI and NNFI were high. In contrast, for the CDSII, higher values for RMSEA (.10) and SRMR (.13) have been reported in a failure condition (Ingledew et al., 1996), and lower values for CFI (from .87 to .92) have been reported across team and individual sports subsamples, and male and female subsamples (Crocker et al., 2002).

Across the two conditions, factor loadings for the CSGU ranged from .56 to .91 for all models except for one item. The factor loading of the stability item "does not fluctuate across performances" was .42 in the least successful condition. In Studies 2 and 3, the item was reworded "fluctuates across performances" and reverse scored. Support for the modification to the item was provided in Study 2: The reworded item resulted in a higher factor loading of .60. Factor correlations 
for the CSGU ranged from .04 (between stability and universality) to .41 (between globality and universality). In contrast, higher factor correlations of .49 (Ingledew et al., 1996), .71 (McAuley et al., 1992), and .91 (Crocker et al., 2002) between personal control and locus of causality have been reported for the CDSII.

The factor structure of the CSGU was tested for factorial invariance across conditions. Support was provided for configural, measurement, and structural factorial invariance (see Byrne, 1998, 2006). Evidence for configural invariance suggests that there is the same number of common factors (i.e., attribution dimensions) across conditions and that each common factor is associated with identical item sets. Evidence for measurement invariance suggests that the items of the CSGU operate equivalently across conditions. In other words, the items are perceived and interpreted the same across conditions. Evidence for structural invariance suggests that the relationships among the factors are similar across conditions. This means that although there is some evidence that the interfactor correlations differ across conditions (i.e., for those involving stability), the magnitude of change in corresponding interfactor correlations across conditions is not significant.

In Study 2, a good fit was observed for the CSGU to data with an independent sample. As predicted, the controllability and stability subscales of the CSGU were significantly and positively associated with the personal control and stability subscales of the CDSII, respectively. These results provide initial evidence of concurrent validity for the controllability and stability subscales of the CSGU. As previous research (e.g., Crocker et al., 2002; Ingledew et al., 1996; McAuley et al., 1992) has found, there was a significant relationship between the locus of causality and personal control subscales of the CDSII $(r=.59, p<.01)$, suggesting that these dimensions are very similar. Across measures, although significant, the strength of the relationship between the controllability subscale of the CSGU and the locus of causality subscale of the CDSII was somewhat weaker $(r=.28$, $p<.01)$. The locus of causality subscale of the CDSII was significantly $(p<.01)$ associated with all of the subscales assessed by the CDSII and the CSGU, suggesting that, in general, there is little evidence of discriminant validity for the locus of causality dimension.

The results of Study 3 demonstrate the potential theoretical and applied implications for examining an expanded conceptualization of generalizability dimensions. That is, in addition to examining whether causes generalize across time (stability), it is also important to examine whether causes generalize across situations (globality) and/or all people (universality). Main effects were reported for controllability, globality, and universality upon self-efficacy. In other words, after less successful performances, individuals had higher self-efficacy when they perceived causes of performance as controllable, and/or specific (perceived as likely to affect a narrow range of situations), and/or universal (perceived as likely to affect all people). These results suggest that in addition to controllability and stability (e.g., Bond et al., 2001; Gernigon \& Delloye, 2003), the generalizability dimensions of globality and universality affect self-efficacy beliefs.

The results of Study 3 also demonstrate the importance of examining interactive effects of attribution dimensions. There was an interactive effect for controllability and stability upon self-efficacy. The interaction demonstrated that if causes were perceived as relatively stable ( $\geq-.87 S D$ in the level of stability), higher levels of 
controllability were associated with higher levels of self-efficacy. In other words, it is particularly important for athletes to perceive control over causes of less successful performances when athletes also perceive that the causes are likely to recur in the future. These results demonstrate that a greater understanding of the nature of relationships between attribution dimensions and outcomes, such as selfefficacy, can be gained from examining interactive effects for controllability and generalizability dimensions.

The CSGU requires participants to rate the most important reason for performance. It might be argued that this may have the disadvantage that the effect of other potential reasons are not captured by the dimension scores. On the other hand, if participants state more than one reason, they might respond to items with an overall average rating in mind or they might just consider the most salient reason (see Biddle \& Hanrahan, 1998). There may be no solution to this dilemma, other than having respondents complete attribution measures for all reasons, separately. In general, researchers have tended to ask participants for the single most important reason (or primary/main cause) for performance (e.g., Gernigon \& Delloye, 2003; Orbach, Singer, \& Price, 1999), and this is the strategy we incorporated into the structure of the CSGU.

The factor structure of the CSGU was confirmed across two independent samples. The mean ages of the samples in the present article ranged from 20.01 to 22.83 years, and all participants were Caucasian British citizens. Future research is necessary to determine whether the factor structure of the CSGU generalizes to athletes of different ages, nationalities, and ethnicities. In the present research, data from team and individual sport athletes were collated before analysis. Crocker et al. (2002) found differential fits for the CDSII across team and individual sports. Future research should examine whether the factor structure of the CSGU is invariant across team and individual sports. Studies 2 and 3 of the present article focused upon attributions following less successful performances. Consequently, no psychometric support for the CSGU following more successful performances was provided beyond support for the factor structure of the CSGU in the most successful condition in Study 1. Future research might further examine the psychometric properties of the CSGU following more successful performances.

In summary, this article has provided initial evidence of construct validity for the CSGU. We hope that the findings herein will encourage researchers to examine the interactive effects of controllability and the generalizability dimensions of stability, globality, and universality attributions upon outcomes such as self-efficacy, emotions, and performance.

\section{Notes}

1. The differences in the magnitude of the correlations between studies may be a reflection of how data were analyzed (success/failure vs. individual/team sports).

2. This conceptualization of controllability is somewhat different from the assessment of personal and external control in the CDSII (McAuley et al., 1992). Of course, Biddle and colleagues (Biddle \& Hanrahan, 1998; Biddle et al., 2001) noted that the assessment of personal and external control is not congruent with Weiner's $(1979,1985)$ model, upon which the CDSII is based. We share the opinions of Skinner (1996) and Anderson and colleagues (e.g., Anderson \& Riger, 1991) 
that the control-by-the-person definition of controllability (or perceived personal control) is the most important aspect of controllability to assess.

3. Marsh, Hau, and Wen (2004) recently expressed concern about the widespread incorporation of such stringent guidelines and cautioned against treating current "rules of thumb" (i.e., the recommendations for fit of $\mathrm{Hu} \&$ Bentler, 1999) as if they were golden rules. Indeed, $\mathrm{Hu}$ and Bentler never intended their guidelines to be interpreted as universal golden rules or absolute cutoff values.

4. Coefficient alpha assumes parallel measures and represents a lower bound estimate of internal reliability (Bollen, 1989; Miller, 1995). In CFA, the items/factors are weighted unequally based on their reliability, with relatively higher weights for items with greater reliability: A better estimate can be gained using the composite reliability formula. Composite reliability $\rho c$ is defined as follows (adapted from Fornell \& Larcker, 1981):

$$
\rho_{c}=\frac{\left(\sum L_{i}\right)^{2}}{\left(\sum L_{i}\right)^{2}+\sum \operatorname{Var}\left(E_{i}\right)}
$$

where $L i$ represents the standardized factor loadings for that factor and $\operatorname{Var}(E i)$ is the error variance associated with the individual indicator variables (items).

5. Shared variance $\rho v c$ is defined as follows (adapted from Fornell \& Larcker, 1981):

$$
\rho_{v c}=\frac{\sum L_{i}{ }^{2}}{\sum L_{i}{ }^{2}+\sum \operatorname{Var}\left(E_{i}\right)}
$$

where $L i$ represents the standardized factor loadings for that factor, and $\operatorname{Var}(E i)$ is the error variance associated with the individual indicator variables (items).

6. The $\Delta \chi^{2}$ is as sensitive to sample size and non-normality as is the $\chi^{2}$ statistic itself (Cheung \& Rensvold, 2002; Marsh, Hey, Roche, \& Perry, 1997). There is an increasing tendency (see Byrne, 2006) to argue for evidence of invariance based on two alternative criteria: (a) the value of $\Delta C F I$ between models is negligible (Cheung \& Rensvold, 2002, suggested that a value of $\Delta$ CFI smaller than or equal to -.01 indicates that the null hypothesis of invariance should not be rejected), and (b) the overall model exhibits an adequate fit to the data.

7. The value of -.87 reflects the precise value of the modifying variable (i.e., stability) when the marginal effect of the focal independent variable (i.e., controllability) becomes significant. From a basic model:

$$
Y=b_{0}+b_{1} X+b_{2} Z+b_{3} X Z
$$

the marginal effect of $\mathrm{X}$ is

$$
\frac{d y}{d x}=b_{1}+b_{3} Z
$$

and the standard error is

$$
S E=\sqrt{\operatorname{Var}\left(b_{1}\right)+Z^{2} \operatorname{Var}\left(b_{3}\right)+2 Z \operatorname{Cov}\left(b_{1} b_{3}\right)}
$$


where $Y$ is the dependent variable, $X$ is the focal independent variable, $Z$ is the modifying variable, $b_{0}$ is the constant, $b_{1}$ is the regression coefficient for $X, b_{2}$ is the regression coefficient for $Z, b_{3}$ is the regression coefficient for $X Z, d y / d x$ is the marginal effect of $X$ (gradient of the regression line), $S E$ is the standard error, Var is the variance, and Cov is the covariance. Note that the standard error is used to calculate the confidence intervals. For more information, the reader is referred to Brambor, Clark, and Golder (2005) and to Preacher, Curran, and Bauer (2006).

\section{Acknowledgments}

The authors would like to thank Professor Lew Hardy (School of Sport, Health, and Exercise Sciences, University of Wales, Bangor) for his assistance in developing items for the CSGU.

\section{References}

Abramson, L.Y., Seligman, M.E.P., \& Teasdale, J.D. (1978). Learned helplessness in humans: Critique and reformulation. Journal of Abnormal Psychology, 87, 49-74.

Anderson, C.A., \& Riger, A.L. (1991). A controllability attributional model of problems in living: Dimensional and situational interactions in the prediction of depression and loneliness. Social Cognition, 9, 149-181.

Bandura, A. (1997). Self-efficacy: The exercise of control. New York: Freeman.

Bentler, P.M. (1990). Comparative fit indexes in structural models. Psychological Bulletin, 103, 411-423.

Biddle, S.J.H. (1993). Attribution research and sport psychology. In R.N. Singer, M. Murphey, \& L.K. Tennant (Eds.), Handbook of research on sport psychology (pp. 437-464). New York: Macmillan.

Biddle, S.J.H., \& Hanrahan, S.J. (1998). Attributions and attributional style. In J.L. Duda (Ed.), Advances in sport and exercise psychologymeasurement (pp. 3-19). Morgantown, WV: Fitness Information Technology.

Biddle, S.J.H., Hanrahan, S.J., \& Sellars, C.N. (2001). Attributions: Past, present, and future. In R.N. Singer, H.A. Hausenblas, \& C.M. Janelle (Eds.), Handbook of sport psychology (2nd ed., pp. 444-471). New York: Wiley.

Bollen, K.A. (1989). Structural equations with latent variables. New York: Wiley.

Bond, K.A., Biddle, S.J.H., \& Ntoumanis, N. (2001). Self-efficacy and causal attribution in female golfers. International Journal of Sport Psychology, 31, 243-256.

Brambor, T., Clark, W.R., \& Golder, M. (2005). Understanding interaction models: Improving empirical analyses. Political Analysis, 14, 63-82.

Browne, M.W., \& Cudeck, R. (1993). Alternative ways of assessing model fit. In K.A. Bollen \& J.S. Long (Eds.), Testing structural equation models (pp. 136-162). Newbury Park, CA: Sage.

Byrne, B.M. (1998). Structural equation modeling with LISREL, PRELIS, and SIMPLIS: Basic concepts, applications, and programming. Mahwah, NJ: Lawrence Erlbaum Associates.

Byrne, B.M. (2006). Structural equation modeling with EQS: Basic concepts, applications, and programming (2nd ed.). Mahwah, NJ: Lawrence Erlbaum Associates.

Carver, C.S. (1989). How should multifaceted personality constructs be tested? Issues illustrated by self-monitoring, attributional style, and hardiness. Journal of Personality and Social Psychology, 56, 577-585.

Cheung, G.W., \& Rensvold, R.B. (2002). Evaluating goodness-of-fit indexes for testing measurement invariance. Structural Equation Modeling, 9, 233-255. 
Crocker, P.R.E., Eklund, R.C., \& Graham, T.R. (2002). Evaluating the factorial structure of the revised causal dimension scale in adolescents. Research Quarterly for Exercise and Sport, 73, 211-218.

Dunn, G.H., Bouffard, M., \& Rogers, W.T. (1999). Assessing item content-relevance in sport psychology scale-construction research: Issues and recommendations. Measurement in Physical Education and Exercise Science, 3, 15-36.

Fornell, C., \& Larcker, D.G. (1981). Evaluating structural equation models with unobservable variables and measurement error. JMR, Journal of Marketing Research, 18, 39-50.

Gernigon, C., \& Delloye, J. (2003). Self-efficacy, causal attribution, and track athletic performance following unexpected success or failure among elite sprinters. The Sport Psychologist, 17, 55-76.

Hardy, L., Jones, J.G., \& Gould, D. (1996). Understanding psychological preparation for sport: Theory and practice of elite performers. Chichester: Wiley.

Hu, L., \& Bentler, P.M. (1999). Cutoff criteria for fit indexes in covariance structure analysis: Conventional criteria versus new alternatives. Structural Equation Modeling, 6, $1-55$.

Ingledew, D.K., Hardy, L., \& Cooper, C.L. (1996). An attributional model applied to health behavior change. European Journal of Personality, 10, 111-132.

Jaccard, J., Turrisi, R., \& Wan, C.K. (1990). Interaction effects in multiple regression. Newbury Park, CA: Sage.

Jöreskog, K.G. (1993). Testing structural equation models. In K.A. Bollen \& J.S. Long (Eds.), Testing structural equation models (pp. 294-316). Newbury Park, CA: Sage.

Jöreskog, K.G., \& Sörbom, D. (1989). LISREL 7 user's reference guide. Chicago, IL: Scientific Software International.

Jöreskog, K.G., \& Sörbom, D. (1996). LISREL 8 user's reference guide. Chicago, IL: Scientific Software International.

Mantler, J., Schellenberg, E.G., \& Page, J.S. (2003). Attributions for serious illness: Are controllability, responsibility, and blame different constructs? Canadian Journal of Behavioural Science, 35, 142-152.

Marlatt, G.A., \& Gordon, J.R. (1985). Relapse prevention: Maintenance strategies in the treatment of addictive behaviors. New York: Guildford Press.

Marsh, H.W., Hau, K.T., \& Wen, Z. (2004). In search of golden rules: Comment on hypothesis-testing approaches to setting cutoff values for fit indexes and dangers in overgeneralizing Hu and Bentler's (1999) findings. Structural Equation Modeling, 11, 320-341.

Marsh, H.W., Hey, J., Roche, L.A., \& Perry, C. (1997). Structure of physical self-concept: Elite athletes and physical education students. Journal of Educational Psychology, 89, 369-390.

McAuley, E. (1985). Success and causality in sport: The influence of perception. Journal of Sport Psychology, 7, 13-22.

McAuley, E., Duncan, T.E., \& Russell, D. (1992). Measuring causal attributions: The revised Causal Dimension Scale (CDSII). Personality and Social Psychology Bulletin, $18,566-573$.

Miller, M.B. (1995). Coefficient alpha: A basic introduction from the perspectives of classical test theory and structural equation modeling. Structural Equation Modeling, 2, 255-273.

Nunnally, J.C. (1978). Psychometric theory (2nd ed.). New York: McGraw-Hill.

Orbach, I., Singer, R., \& Price, S. (1999). An attribution training program and achievement in sport. The Sport Psychologist, 13, 69-82.

Preacher, K.J., Curran, P.J., \& Bauer, D.J. (2006). Computational tools for probing interaction effects in multiple linear regression, multilevel modeling, and latent curve analysis. Journal of Educational and Behavioral Statistics, 31, 437-448. 
Raykov, T. (2006). Examining temporal stability of scale validity in longitudinal studies. Multivariate Behavioral Research, 41, 401-426.

Rees, T., Ingledew, D.K., \& Hardy, L. (2005). Attribution in sport psychology: Seeking congruence between theory, research and practice. Psychology of Sport and Exercise, 6, 189-204.

Rejeski, W.J., \& Brawley, L.R. (1983). Attribution theory in sport: Current status and new perspectives. Journal of Sport Psychology, 5, 77-99.

Russell, D. (1982). The Causal Dimension Scale: A measure of how individuals perceive causes. Journal of Personality and Social Psychology, 42, 1137-1145.

Schutz, R.W., \& Gessaroli, M.E. (1993). Use, misuse, and disuse of psychometrics in sport psychology research. In R.N. Singer, M. Murphy, \& L.K. Tennant (Eds.), Handbook of research on sport psychology (pp. 901-917). New York: Macmillan.

Shook, C.L., Ketchen, D.J., Hult, G.T.M., \& Kacmar, K.M. (2004). An assessment of the use of structural equation modeling in strategic management research. Strategic Management Journal, 25, 397-404.

Skinner, E.A. (1996). A guide to constructs of control. Journal of Personality and Social Psychology, 71, 549-570.

Steiger, J.H. (1990). Structural model evaluation: An interval estimation approach. Multivariate Behavioral Research, 25, 173-180.

Streiner, D.L., \& Norman, G.R. (1995). Health measurement scales: A practical guide to their development and use (2nd ed.). New York: Oxford University Press.

Sudman, S., Bradburn, N.M., \& Schwarz, N. (1996). Thinking about answers: The application of cognitive processes to survey methodology. San Francisco, CA: Jossey-Bass.

Tucker, L.R., \& Lewis, C. (1973). A reliability coefficient for maximum likelihood factor analysis. Psychometrika, 38, 1-10.

Vallerand, R.J. (1987). Antecedents of self-related affects in sport: Preliminary evidence on the intuitive-reflective appraisal model. Journal of Sport Psychology, 9, 161-182.

Weiner, B. (1979). A theory of motivation for some classroom experiences. Journal of Educational Psychology, 71, 3-25.

Weiner, B. (1985). An attributional theory of achievement motivation and emotion. Psychological Review, 92, 548-573.

Wong, P.T.P., \& Weiner, B. (1981). When people ask "why" questions, and the heuristics of attributional search. Journal of Personality and Social Psychology, 40, 650-663.

Manuscript submitted: May 31, 2007

Revision accepted: May 26, 2008 


\section{Appendix}

In the space below, write the single most important reason for how you performed.

The most important reason was

Think about the reason you have written above. Please indicate to what extent the statements below relate to your reason by circling the most appropriate number from 1 (meaning not at all) to 5 (meaning completely).

$1=$ not at all

$2=$ a little

$3=$ somewhat

$4=\mathrm{a}$ lot

$5=$ completely

In general, to what extent is your reason something that ...

$$
\text { not at all a little somewhat a lot completely }
$$

1. you could control in the future

2. remains stable across time

$\begin{array}{lllll}1 & 2 & 3 & 4 & 5 \\ 1 & 2 & 3 & 4 & 5 \\ 1 & 2 & 3 & 4 & 5 \\ 1 & 2 & 3 & 4 & 5\end{array}$

4. affects your performance on all tasks

5. other athletes give as a cause to explain their performances

$\begin{array}{lllll}1 & 2 & 3 & 4 & 5\end{array}$

6. is a wide-ranging cause, affecting you in all situations

7. you feel remains constant over time

$\begin{array}{lllll}1 & 2 & 3 & 4 & 5 \\ 1 & 2 & 3 & 4 & 5\end{array}$

8. other athletes believe affects their performances

9. you could alter in the future

$\begin{array}{lllll}1 & 2 & 3 & 4 & 5 \\ 1 & 2 & 3 & 4 & 5\end{array}$

10. does not change from one of your performances to the next

11. in the future, you could exert control over

$\begin{array}{lllll}1 & 2 & 3 & 4 & 5 \\ 1 & 2 & 3 & 4 & 5\end{array}$


In general, to what extent is your reason something that ...

not at all a little somewhat a lot completely

12. is a common cause of performance for other athletes

$\begin{array}{lllll}1 & 2 & 3 & 4 & 5\end{array}$

13. relates to a number of different situations you encounter

14. does not fluctuate across performances

$\begin{array}{lllll}1 & 2 & 3 & 4 & 5 \\ 1 & 2 & 3 & 4 & 5\end{array}$

15. is a cause of performance that other athletes relate to

16. $\begin{array}{lllllll}\text { affects a wide variety of outcomes for you } & 1 & 2 & 3 & 4 & 5\end{array}$

17. In the future, you could change at will $\quad \begin{array}{lllllll}1 & 2 & 3 & 4 & 5\end{array}$

18. influences the outcomes of new situations you face

19. does not vary across time

20. you could regulate in the future

$\begin{array}{lllll}1 & 2 & 3 & 4 & 5 \\ 1 & 2 & 3 & 4 & 5 \\ 1 & 2 & 3 & 4 & 5\end{array}$

21. can be used to explain the performances of other athletes

22. stays consistent across time

23. influences all situations you encounter

$\begin{array}{lllll}1 & 2 & 3 & 4 & 5 \\ 1 & 2 & 3 & 4 & 5\end{array}$

24. is a cause of performance for other athletes as well

$\begin{array}{lllll}1 & 2 & 3 & 4 & 5\end{array}$

Note. Boldface indicates items that were retained and were used in studies 2 and 3 (except for the item "does not fluctuate across performances," which was reworded "fluctuates across performances" and reverse scored). The total scores for each dimension are obtained by calculating the mean average of items, as follows:
$1,3,9,11,17,20=$ controllability
2, 7, 10, 14, 19, $22=$ stability
$4,6,13,16,18,23=$ globality
$5,8, \mathbf{1 2}, \mathbf{1 5}, \mathbf{2 1}, \mathbf{2 4}=$ universality 